Original Research

\title{
Prevalence of the Glycogen Branching Enzyme Deficiency Mutation in Quarter Horses in Brazil
}

\author{
César E.T. Araujo ${ }^{a}$, Diego J.Z. Delfiol ${ }^{\mathrm{b}}$, Peres R. Badial ${ }^{\mathrm{c}}$, José P. Oliveira-Filho ${ }^{\mathrm{a}}$, \\ João P. Araujo-Junior ${ }^{\mathrm{d}}$, Alexandre S. Borges ${ }^{\mathrm{a}, *}$
}

${ }^{a}$ Department of Veterinary Clinical Science, School of Veterinary Medicine and Animal Science, Universidade Estadual Paulista, Botucatu, São Paulo, Brazil

${ }^{\mathrm{b}}$ School of Veterinary Medicine, Universidade Federal de Uberlândia, Uberlândia, Minas Gerais, Brazil

${ }^{\mathrm{c}}$ Department of Pathobiology and Population Medicine, College of Veterinary Medicine, Mississippi State University, Starkville, MS

${ }^{\mathrm{d}}$ Department of Microbiology, Institute of Biosciences, Universidade Estadual Paulista, Botucatu, São Paulo, Brazil

\section{A R T I C L E I N F O}

\section{Article history:}

Received 8 August 2017

Received in revised form 6 October 2017

Accepted 6 October 2017

Available online 14 October 2017

\section{Keywords:}

Abortion

Glycogen

Foal

Muscle disease

Hereditary disease

\begin{abstract}
A B S T R A C T
Glycogen branching enzyme deficiency (GBED) is a fatal autosomal inherited disease affecting horses and caused by a nonsense mutation (c.102C $>$ A) in the GBE1 gene. This disease strongly impairs the glycogen metabolism of affected animals resulting in abortion or early death of foals. Although understanding the prevalence of heterozygous for GBED is imperative to estimate the impact of the disease, prevalence studies have yet to be performed in Brazil. The aim of this study was to determine the prevalence of heterozygous of the GBED mutation in a population of Quarter Horses in Brazil. Blood samples were obtained from 742 animals competing in distinct disciplines including cutting, halter, race, reining, and barrel racing. All samples were submitted to DNA purification, amplification, and sequencing of the target fragment. The overall GBED prevalence of carriers was 7.95\% (59/742). The prevalence of heterozygotes by discipline was considered higher in cutting (19.75\% [32/162]) and reining (10\% [16/160]) subgroups followed by barrel racing (5\% [8/160]) and halter (3\% [3/100]) horses. There were none heterozygous in the racing subgroup. These results demonstrate the GBED causative mutation in the Brazilian Quarter Horse herd and suggest the occurrence of the disease. Therefore, GBED is a disease that should be considered in the differential diagnosis of abortion and stillbirths, especially if suspect foals are products of two heterozygous. Besides testing aborted foals for the GBED mutation, the molecular diagnosis should be recommended to owners and breeders, at least for those breeding the at-most-risk subgroups of horses, to guiding their mating selections and, therefore, prevent the transmission of the mutation.
\end{abstract}

(c) 2017 Elsevier Inc. All rights reserved.

\section{Introduction}

Brazil, the fifth largest exporter of Quarter Horse $(\mathrm{QH})$, has over 5,000 animals registered in the Quarter Horse Brazilian Breeders Association [1,2]. Eighteen diseases with

\footnotetext{
Animal welfare/ethical statement: All procedures were approved by the Board of Ethics and Animal Experimentation of the institution (protocol no 262/2011-CEUA).

Conflict of interest statement: The authors declare no conflicts of interest.

* Corresponding author at: Alexandre S. Borges, Doutor Walter Mauricio Correa St, Unesp-Botucatu, 18618-68 Botucatu, SP, Brazil.

E-mail address: asborges@fmvz.unesp.br (A.S. Borges).
}

hereditary pattern are recognized in the $\mathrm{QH}$ breed, of which five have its molecular defect elucidated: hyperkalemic periodic paralysis (HYPP) [3], glycogen branching enzyme deficiency (GBED) [4], hereditary equine regional dermal asthenia [5], polysaccharide storage myopathy 1 [6], and malignant hyperthermia [7].

Glycogen branching enzyme deficiency was first described in humans (a.k.a. glycogenosis type IV) [8] and features three clinical variants with neuromuscular involvement, the congenital, juvenile, and adult forms [9]. This clinical heterogeneity is related to different mutations identified along the GBE1 gene [10]. 
In horses, GBED is a fatal autosomal recessive monogenic disease affecting animals of the $\mathrm{QH}$ and Paint Horse breeds. The disease is caused by a nonsense mutation in exon 1 of $G B E 1$ (c.102C $>A$ ) resulting in a premature stop codon (TAA) and, therefore, incomplete translation and synthesis of glycogen branching enzyme (glycosyl 4,6 transferase) [4].

Glycogen branching enzyme is important for glycogenesis because it catalyzes the formation of branching points in the glycogen molecule. The tissues of affected foals are unable to synthesize normal branched glycogen [11], thereby impairing bioavailability and homeostasis of glucose and promoting the accumulation of abnormal structure and less branched polysaccharide [11-13]. In the absence of glycogen, tissues such as the cardiac muscle, renal pelvis, and brain are unable to maintain adequate activity, which in turn leads to death of foals [11,13].

Clinically, affected foals may have flexural deformities, difficulty or inability to stand, seizures, absence of sucking reflex, signs of cardiorespiratory insufficiency, and sudden death. There is no report of affected foals surviving for more than 18 weeks after birth, even under intensive medical care [4]. Due to abnormal glycogen accumulation in Purkinje fibers and insufficient supply of glucose to the myocardium, these foals present arrhythmias and sudden death when exercised [11]. Accurate diagnosis is performed using molecular tests using blood and/or hair DNA samples from affected animals [14].

Abortions, stillbirths, and premature births also characterize this disease [4,13]. The frequency of abortions in horses can vary, but abortion and stillbirth are important causes of economic loss [15-19]. However, studies conducted in the United Kingdom, France, and the United States determined that in $7.8 \%-25.1 \%$ of the abortion cases, the etiology was not identified [18-20]. In Brazil, this scenario is even worse, and it is estimated that the cause of abortion in horses is unknown in $47.2 \%-54 \%$ of the cases [21,22]. In the United States, $1.3 \%-3.8 \%$ of abortion cases in QHs are caused by GBED [13].

Previous studies in the United States reported a frequency of heterozygous for GBED between 8.3\% [13] and $11 \%$ [23], and higher frequencies were estimated in western pleasure (26.3\%) and cutting subgroups (13.6\%) [13]. It is unknown whether there is the GBED causative mutation in Brazil as well as its prevalence.

The mutation is expected to be present in the Brazilian herd as the genetic basis of these animals derives from QHs in the United States. The aim of this study was to determine the prevalence of heterozygous of the GBED causative mutation in a population of QHs used in five equestrian sports practiced in Brazil.

\section{Material and Methods}

\subsection{Animals}

Considering the total population of QHs in Brazil of 515,000 animals and the published GBED carrier frequency of $8.3 \%$, a sample of at least 731 horses would be needed to estimate the prevalence of the GBED heterozygous in Brazil.
The sample size was calculated under a margin of error of $2 \%$ and $95 \%$ confidence interval [24].

Seven hundred forty-two QHs were selected, from both genders, older than 6 months of age, and competing in five distinct disciplines: cutting $(n=162)$, halter $(n=100)$, race ( $n=160)$, reining $(n=160)$, and barrel racing $(n=160)$. The convenience sampling included the participation of 42 stud farms and/or training centers in São Paulo and Rio Grande do Sul states. Blood samples were collected with ethylenediamine tetraacetic acid anticoagulant from all animals under strict confidentiality agreement to ensure the anonymity of farms, owners, and animals. These samples were kept under refrigeration until the DNA isolation. All procedures were approved by the Board of Ethics and Animal Experimentation of the institution (protocol no 262/ 2011-CEUA).

\subsection{DNA Purification}

DNA was purified from blood samples using a commercial kit (Ilustra Blood GenomicPrep Mini Spin Kit [GE Healthcare]) following the manufacturer's recommendations. The DNA was diluted in $100 \mu \mathrm{L}$ of water-free DNase and RNase. A sample of $2 \mu \mathrm{L}$ DNA was tested for purity (A260/280) and concentration using a spectrophotometer and immediately stored at $-80^{\circ} \mathrm{C}$.

\subsection{Polymerase Chain Reaction}

The PCR was designed to amplify a 267 base pairs fragment of the GBE1 gene by using samples of genomic DNA and primers [4]. The standard reactions were prepared to a final volume of $25 \mu \mathrm{L}$, including $2.0 \mu \mathrm{L}$ of DNA, $11 \mu \mathrm{L}$ of master mix (GoTaq Green Master Mix, 2× [Promega]), 0.4 $\mu \mathrm{M}$ of each primer, $4.0 \mu \mathrm{L}$ of PCRx enhancer solution (Invitrogen) (final concentration of $1.6 \mathrm{X}$ reaction), and nuclease-free water q.s.p. Polymerase chain reactions were used with the following programmed cycles (Mastercycler EP Gradient S Eppendorf, Hamburgo, Alemanha): $95^{\circ} \mathrm{C}$ for 5 minutes followed by 35 cycles of $95^{\circ} \mathrm{C}$ for 30 seconds, $59^{\circ} \mathrm{C}$ for 1 minute, and $72^{\circ} \mathrm{C}$ for 1 minute and final extension at $72^{\circ} \mathrm{C}$ for 7 minutes.

\subsection{Agarose Gel Electrophoresis}

The size of the amplified products was confirmed by electrophoresis (Major Science, Saratoga, CA) system using stained (GelRed [Biotium, Halward, CA]) 1.5\% agarose gel and compared to the DNA ladder (LowRanger $100 \mathrm{pb}$ DNA [Norgen, BioTek Corporation, Ontario, Canada]), and then, the gels were documented (ImageQuantimager [GE Healthcare]).

\subsection{Purification of the Amplified Products}

The amplified products were purified with a commercial kit (PCR cleanup Gel extraction kit [Macherey-Nagel, Duren, Germany]), according to the manufacturer's recommendation. After purification, the concentration was standardized to $10 \mathrm{ng} / \mu \mathrm{L}$ and submitted to sequencing reaction. 


\subsection{Sequencing Reaction}

The sequencing reaction was prepared to a final volume of $10 \mu \mathrm{L}: 1.0 \mu \mathrm{L}$ of the forward primer used in the PCR at 5 $\mu \mathrm{M}, 2 \mu \mathrm{L}$ (approximately $20 \mathrm{ng}$ ) of the purified amplified product, $1.0 \mu \mathrm{L}$ of comercial mix (BigDye Terminator v3.1 Cycle Sequencing Kit [Applied Biosystems, Foster City, CA]), $1.5 \mu \mathrm{L}$ of buffer solution (BigDye Terminator v1.1 \& v3.1 5X Sequencing Buffer [Applied Biosystems]), and water "nuclease-free" q.s.p. After preparing the reaction, all samples were subjected to automated direct sequencing with 3500 Genetic Analyzers (AppliedBiosystems, Foster City, CA). After sequencing, the quality control of the sequences and obtained electropherograms was analyzed using the appropriate software (Sequencing Analysis 5.3.1 [Applied Biosystems]).

\subsection{Analysis of the Sequences}

The sequences were aligned against the GBE1 reference genome sequence (accession number AY505110.1) available in the National Center for Biotechnology Information database using the BLAST tool (Basic Local Alignment Search Tool) to determine that a fragment of the equine $G B E 1$ gene was amplified. After confirmation, the nucleotide sequences and electropherograms were analyzed using an appropriate software (Ridom TraceEdit [Ridom GmbH, Münster, Germany]), enabling genotypic identification.

\subsection{Data Analysis}

The genotype data analysis was performed using SAS software. The prevalence of heterozygous was calculated, and the prevalences of the subgroups were compared using the chi-square statistical test. Statistical significance was considered for $P \leq .05$.

\subsection{Pedigree Analysis}

All animals had their genealogy traced back to 10 generations, consulting the database of Quarter Horse Brazilian Breeders Association, searching for the presence of the stallions King P-234 and Zantanon, which are considered the major disseminators of the GBED mutation.

\section{Results}

The GBED causative mutation was identified only in heterozygosis in animals with 2.5-29 years of age and in four of the five subgroups studied. All heterozygous had Zantanon or King P-234, at least once, in their pedigree in either the mare and/or sire bloodlines. King P-234 was found, on average, six times in each horse's pedigree. On the other hand, pedigree analysis of the wild-type homozygous horses showed inconsistent parentage with King P-234 or Zantanon.

Of the 42 farms that collaborated with the study, 20 (47.62\%) had at least one heterozygous horse. There was at least one heterozygous in 53.33\% (8/15), 50\% (11/22), $27.77 \%(5 / 18)$, and $15.38 \%(2 / 13)$ of farms with cutting, reining, barrel racing, and halter horses, respectively.
From the 742 animals tested, 59 were heterozygous for the mutation responsible for GBED representing a prevalence of $7.95 \%$ (59/742) in the studied population. The prevalence was significantly different among subgroups $(P<.05$ and $\mathrm{DF}=4)$. The prevalence of heterozygous was highest in cutting horses (19.75\% [32/162]), followed by reining (10\% [16/160]), barrel racing (5\% [8/160]), and halter (3\% [3/100]) subgroups. We did not detect any carriers among racing horses. There was no statistical difference $(P<.05$ and DF $=1)$ between the frequency of carriers in both genders (not shown).

\section{Discussion}

It is not surprising that the mutation was not identified in homozygosis since the minimum age of the animals in this study was six months and that GBED is a fatal disease causing death in up to 18 weeks of life [4].

Although it is well known that the genetic basis of the Brazilian Quarter Horse herd is derived from the American herd [25] and there are previous studies that had already identified the presence of GBED-affected foals and heterozygous animals in the United States, it was not possible to affirm that the GBED mutation was present in the Brazilian herd. This is the first study to reveal the prevalence of heterozygous for GBED in Brazil. Considering that the prevalence of heterozygous in Brazil (7.95\%) is similar to that in the United States $(8.3 \%-11 \%)$ [13,23], it is likely that the same situation may be found in other countries, given that the United States is the largest exporter of QHs and Brazil ranks as the fifth larger. In 2016, the United States exported 45,123 animals, with is a much greater number than all other countries combined $(2,618$ animals $)$ in the same time frame [2].

Similar to a previous study [23], different frequencies of heterozygous were identified in cutting, reining, barrel racing, and halter horses, and no heterozygous were identified in the racing subgroup. A higher prevalence of heterozygotes was observed in the reining subgroup (10\%) compared to the halter subgroup (3\%). However, Tryon et al (2009) demonstrated a higher rate of heterozygotes in halter subgroup (5.1\%) compared to subgroup reining (3.1\%). For the subgroup barrel racing, it was found 5\% of heterozygotes in this study and $1.2 \%$ by Tryon et al (2009). In cutting subgroup, it was found $19.75 \%$ of heterozygous, but for the same subgroup, the rate observed in United States was 13.6\% [23]. However, Tryon et al (2009) sampled among 100 top ranked performers QHs, whereas the current study sampled among farms. The differences in sampling methods and population structure may justify the discrepancy in prevalence between the studies [23].

The higher prevalence in cutting and reining groups may be associated with the fact that King P-234 sired horses with characteristics that are desirable in the cutting and reining lineages. This may justify the higher prevalence of heterozygous observed in those groups compared to the others groups. Animals belonging to these bloodlines are more likely of being heterozygous or affected homozygous.

The reproductive history of the animals was not obtained in the present study. Therefore, it is unknown how many abortions and/or stillbirths were produced from matings 
between heterozygotes, and what diagnoses were established. Analysis of the mares' reproductive history along with the molecular testing of aborted or stillborn foals would explain how many of those animals were homozygous for the GBED mutation. Considering that in the last 5 years, more than 130,000 horses were registered in the Brazilian Association and the overall prevalence of heterozygotes for GBED of 7.95\%, it can be estimated that more of 10,000 heterozygotes were registered in that period. As one would expect from a disease that follows a Mendelian inheritance pattern, the mating of two heterozygous would result in a probability of 0.25 of homozygous offspring for the mutant allele [26]. If the principle of Hardy-Weinberg equilibrium is considered, about 205 GBED-affected foals were conceived and died in the last 5 years in Brazil.

Since the etiology of approximately half of the cases of abortion in Brazil is unknown [21,22] and there is no previous information regarding the prevalence of the disease, it is possible that GBED has been silently contributing to abortion in horses throughout the years and resulting in large economic losses. This highlights the need to know the genotype of the animals to guide the mating selection, avoiding the production of affected foals. Thus, since January 2015, the American Quarter Horse Association (AQHA) requires the five-panel test of genetic diseases, which includes GBED, for the all stallions prior to the registration of their foals [27]. In Brazil, only the genetic test for HYPP is mandatory prior registration of foals. The Brazilian association requires the HYPP genetic testing for all QHs born after July 2004 that are descendants of the stallion Impressive (AQHA 0767246), and, if positive, the animals are no longer registered [28].

\section{Conclusions}

GBE1 gene mutation, responsible for GBED when in homozygosis, is present in the Brazilian $\mathrm{QH}$ population. The causative mutation is more frequent in cutting and reining horses. The results of this study suggest that GBED disease may occur in Brazil; therefore, the GBED should be included in the differential diagnosis list of abortion cases and neonatal mortality in horses. In addition, standardized molecular testing should be used to guide the choice of mating pairs, which is the only preventive measure to avoid production of affected foals.

\section{Acknowledgments}

Financial disclosure: The present research was supported by Fundação de Amparo à Pesquisa do Estado de São Paulo (FAPESP) (2011/23729-0). The first author received a scholarship from Coordenação de Aperfeiçoamento de Pessoal de Nível Superior (CAPES).

\section{References}

[1] ABQM. Quarto de Milha no Brasil, http://www.abqm.com.br/ conteudos/quarto-de-milha/quarto-de-milha-no-brasil. Accessed February 1, 2017

[2] AQHA. AQHA 2015 Annual report. Amarillo, TX: P.O. American Quarter Horse Association; 2015. https://www.aqha.com/media/ 17917/2015-annual-report.pdf. Accessed 13 March 2016.
[3] Rudolph JA, Spier SJ, Byrns G, Rojas CV, Bernoco D, Hoffman EP. Periodic paralysis in quarter horses: a sodium channel mutation disseminated by selective breeding. Nat Genet 1992;2:144-7.

[4] Ward TL, Valberg SJ, Adelson DL, Abbey CA, Binns MM, Mickelson JR. Glycogen branching enzyme (GBE1) mutation causing equine glycogen storage disease IV. Mamm Genome 2004;15:570-7.

[5] Tryon RC, White SD, Bannasch DL. Homozygosity mapping approach identifies a missense mutation in equine cyclophilin B (PPIB) associated with HERDA in the American Quarter Horse. Genomics 2007; 90:93-102.

[6] McCue ME, Valberg SJ, Lucio M, Mickelson JR. Glycogen synthase 1 (GYS1) mutation in diverse breeds with polysaccharide storage myopathy. J Vet Intern Med 2008;22:1228-33.

[7] Aleman M, Nieto JE, Magdesian KG. Malignant hyperthermia associated with ryanodine receptor 1 (C7360G) mutation in Quarter Horses. J Vet Intern Med 2009;23:329-34.

[8] Andersen DH. Familial cirrhosis of the liver with storage of abnormal glycogen. Lab Invest 1956;5:11-20.

[9] Bruno C, Cassandrini D, Assereto S, Akman HO, Minetti C, Di Mauro S. Neuromuscular forms of glycogen branching enzyme deficiency. Acta Myol 2007;26:75-8.

[10] Bao Y, Kishnani P, Wu JY, Chen YT. Hepatic and neuromuscular forms of glycogen storage disease type IV caused by mutations in the same glycogen-branching enzyme gene. J Clin Invest 1996;97:941-8.

[11] Valberg SJ, Ward TL, Rush B, Kinde H, Hiraragi H, Nahey D, et al. Glycogen branching enzyme deficiency in quarter horse foals. J Vet Intern Med 2001;15:572-80.

[12] Sponseller BT, Valberg SJ, Ward TL, Fales-Williams AJ, Mickelson JR Muscular weakness and recumbency in a Quarter Horse colt due to glycogen branching enzyme deficiency. Equine Vet Educ 2003;15: $182-8$

[13] Wagner ML, Valberg SJ, Ames EG, Bauer MM, Wiseman JA, Penedo MC, et al. Allele frequency and likely impact of the glycogen branching enzyme deficiency gene in Quarter Horse and Paint Horse populations. J Vet Intern Med 2006;20:1207-11.

[14] Valberg SJ. Glycogen-branching enzyme deficiency, vol. 52; 2006 Proceedings of the 52nd Annual Convention of the American Association of Equine Practitioners, San Antonio, Texas.

[15] Bain AM. Foetal losses during pregnancy in the thoroughbred mare: a record of 2,562 pregnancies. N Z Vet J 1969;17:155-8.

[16] Whitwell KE. Investigations into fetal and neonatal losses in the horse. Vet Clin North Am Large Anim Pract 1980;2:313-31.

[17] Acland HM. Abortion in mares. In: McKinnon AO, Voss JL, editors. Equine reprodution. Philadelphia, PA: Lea \& Febiger; 1993. p. 554-62.

[18] Hong CB, Donahue JM, Giles Jr RC, Petrites-Murphy MB, Poonacha KB, Roberts AW, et al. Equine abortion and stillbirth in central Kentucky during 1988 and 1989 foaling seasons. J Vet Diagn Invest 1993;5:560-6.

[19] Laugier C, Foucher N, Sevin C, Leon A, Tapprest JA. 24-year retrospective study of equine abortion in Normandy (France). J Equine Vet Sci 2011;31:116-23.

[20] Smith KC, Blunden AS, Whitwell KE, Dunn KA, Wales AD. A survey of equine abortion, stillbirth and neonatal death in the UK from 1988 to 1997. Equine Vet J 2003;35:496-501.

[21] Moreira N, Krünger ER, Warth JFG, Biesdorf SM, Goularte MMM, Weiss RR. Aspectos etiológicos e epidemiológicos do aborto equino. Arch Vet Sci 1998;3:25-30.

[22] Marcolongo-Pereira C, Adrien M de L, Ladeira SRL, Soares MP, AssisBrasil ND, Schild AL. Abortos em equinos na região sul do Rio Grande do Sul: estudo de 72 casos. Pesqui Vet Bras 2012;32:22-6.

[23] Tryon RC, Penedo MC, McCue ME, Valberg SJ, Mickelson JR, Famula TR, et al. Evaluation of allele frequencies of inherited disease genes in subgroups of American Quarter Horses. J Am Vet Med Assoc 2009;234:120-5.

[24] Dean AG, Sullivan KM, Soe MM. OpenEpi: Open Source Epidemiologic Statistics for Public Health; 2013. www.OpenEpi.com. Accessed 16 June 2013.

[25] ABQM. Origem; 2014. http://www.abqm.com.br/index.php? option=com_content\&view=article\&id=233:quarto-de-milha-no-bra sil\&catid=28:a-raca. Accessed 23 May 2015.

[26] Griffiths AJF, Wessler SR, Carroll SB, Doebley J. Introdução à genética. 11th ed. Rio de Janeiro: Guanabara Koogan; 2016.

[27] AQHA. DNA and Parentage Verification; 2016. https://www.aqha com/daily/at-your-service/2016/at-your-service-archive/dna-andparentage-verification/. Accessed 19 September 2017.

[28] ABQM. HYPP - Portal ABQM - Associação Brasileira de Criadores de Cavalo Quarto de Milha; 2017. http://www.abqm.com.br/2015/ index.php?option=com_content\&Itemid $=124 \&$ catid $=36 \& i d=3025$ \&view=article. Accessed 19 September 2017. 